\title{
Tolstoi y A. Machado: «A un olmo seco»
}

\author{
Máximo Brioso Sánchez \\ Manuel Bernal Rodríguez
}

Sobre el poema machadiano «A un olmo seco» se ha ido generando una bibliografía relativamente abundante que ha abordado su estudio desde variadas perspectivas: Gerardo Diego analiza el poema desde el punto de vista formal ${ }^{1}$; sin limitarse a ello, también realiza interesantes apreciaciones sobre este asunto Ernesto Jareño en su estudio «Milagro de la primavera (a propósito de un tópicoliterario)» ${ }^{2}$. Aurora de Albornoz, en «De un árbol sonoro a un olmo seco» ${ }^{3}$, describe, a partir de una sugerente lectura, la evolución del símbolo del árbol en la poesía machadiana y subraya la identificación del alma del poeta con el árbol derribado y polvoriento. Especial atención a los elementos simbólicos del poema dedican A. Cardona y M. Gibert en su «Análisis de los símbolos, proceso narrativo y monólogo interior de «A un olmo seco» de A. Machado»"; una finalidad didáctica parece el propósito de Alicia Redondo Goicochea en su «A un olmo seco» ${ }^{5}$, manifestación reciente de los reiterados comentarios de proyección escolar de que el poema ha sido objeto.

Especial atención merecen los estudios encaminados a precisar las posibles influencias literarias actuantes en el poema. Entre ellos, cabe subrayar la meritoria aportación de Luis Cortés Vázquez, «Ronsard y Machado. Del 'aubepin verdisant' al 'olmo seco'», donde se expone con brillantez «todo lo que une y separa al espino albar verdeante de Ronsard y al olmo seco, hendido por el rayo de Machado» ${ }^{6}$. También en esta línea se sitúa el excelente trabajo de Emesto Jareño, «Nueva aproximación al poema

\footnotetext{
${ }^{1}$ DIEGO, G., «El poema «A un olmo seco» y un soneto ¿oculto o involuntario? », en Campo soriano, 6 , I, 1975.

${ }^{2}$ En Cuadernos Hispanoamericanos, núm. 374, agosto 1981, pp. 364 y ss.

${ }^{3}$ En Archivum, XI, 1961, pp. 330-438.

${ }^{4}$ V̌́ase Antonio Machado, hoy, Actas del Congreso Internacional conmemorativo del cincuentenario de la muerte de Antonio Machado, Sevilla, 1990, IV, pp. 261-268.

${ }^{5}$ En Antonio Machado hoy, , cit., IV, pp. 379-382.

${ }^{6}$ En Strenae. Estudios de Filología histórica dedicados al Profesor Manuel García Blanco. Acta Salmanticensia. Filosofia y Letras XVI. Salamanca, 1962, pp. 121-130.
} 
machadiano «A un olmo seco»» ${ }^{7}$, donde se subraya el carácter de tópico literario de la simbología humanista del árbol y se rastrean abundantes antecedentes literarios del simbolismo arbóreo que pudieran haber sido lecturas machadianas. Sin embargo, las interesantes aportaciones efectuadas por estos estudios para precisar el poso de lecturas que, directa o indirectamente, condicionaron al autor de Campos de Castilla en la creación de este poema no agotan la cuestión: se precisan influjos concretos, pero no se señala antecedente alguno sobre la idea fundamental.

El presente artículo no pretende resolver todas las incógnitas que pudieran suscitarse. Nos proponemos recorrer un camino, que ha permanecido inexplorado hasta hoy, y llamar la atención sobre un texto que, según nuestras noticias, no ha sido tenido en cuenta y que nos parece extraordinariamente interesante para ilustrar la gestación del poema que nos ocupa, así como, de paso, la conocida afición del gran poeta sevillano por la literatura rusa contemporánea, como contexto explicativo de una influencia que puede haber sido determinante.

\section{Un tópico universal}

El motivo central del poema viene constituido por una imagen de carácter universal. La identificación, en general, entre hombre y árbol es un tópico literario que puede documentarse desde la antigüedad clásica, como acertadamente indica E. Jareño en su estudio mencionado. En efecto, considerar el árbol, y en general las plantas, como símbolo de la vida, de la generación y de la regeneración es un tópico literario permanente: El «árbol de la vida» es motivo antiguo y universal y, concretamente, el árbol de hoja caduca «es el símbolo de la regeneración perpetua" ${ }^{8}$. Aunque el estudio, metodológicamente limitado, de Blanca Lampreave Taracido sobre «El mundo clásico de Antonio Machado» ${ }^{9}$ no toma en consideración este tema, no es difícil seleccionar textos clásicos grecolatinos, que muy probablemente hubieran podido ser lecturas de Antonio Machado, en los que este simbolismo resulte patente.

La comparación árbol/hombre (o pueblo) se lee ya en el Antiguo Testamento (por ejemplo, Ezequiel, 31, 1-14). En mitologías como la griega, la metamorfosis en árbol es frecuente $\mathrm{y}$, concretamente, la imagen de la planta o el árbol como símbolo humano abunda en la poesía griega y latina. Es de una delicada expresividad, por ejemplo, cómo se nos describe en el Himno homérico a Afrodita (vv. 269-272) la identificación mítica entre los árboles y cierta especie de Ninfas, cuando les llega a éstas su hora final:

${ }^{7}$ En Homenaje a Álvaro Galmés de Fuente, Oviedo, 1985, pp. 465-481.

${ }^{8}$ Cfr. J. CHEVALIER y A. SHEERBRANT, Diccionario de los símbolos (s. v. «árbol», p.119. Trad. esp. Barcelona, Herder, 1986). Cfr. también M. ELIADE, Traité d' histoire des religions, París, reed. 1964, citado por Chevalier-Sheerbrant. 500 .

${ }^{9}$ En Actas del II Congreso Español de Estudios Clásicos, Soc. Esp. de Est. Clás., Madrid 1964, pp. 489 - 
«Mas cuando ya se les presenta el sino de su muerte, primero se secan sobre la tierra los hermosos árboles y su corteza en torno se descompone y se desprenden sus ramas y a la vez el alma de ellas la luz del sol abandona».

Por circunscribirnos sólo a ciertos textos que pudo conocer Machado, citemos que en Homero hay varios símiles en que el guerrero es comparado con un árbol, ya sea por su fortaleza inconmovible, ya sea, por el contrario, por ser derribado en el combate ${ }^{10}$. Es también conocido el pasaje de la Ilíada (VI 146 ss.):

"Cual la generación de las hojas, tal también la de los hombres. las hojas las desparrama por tierra el viento, pero otras el bosque, al renovarse, las hace brotar y sobreviene la estación primaveral; asf la generación de los hombres, la una crece, la otra decae».

Por su parte, Virgilio, Eneida, VI, 309 s., compara la multitud de las sombras de los muertos con las hojas, al modo homérico:

«Quam multa in siluis autumni frigore primo labsa cadunt folia...»

Y Horacio (Odas IV, 4, 57 ss.), parafraseando a Píndaro, compara el pueblo romano a una encina que, talada una y otra vez, siempre se renueva:

«Duris ut ilex tonsa bipennibus

nigrae feraci frondis in algido

per damna, per caedes ab ipso

ducit opes animumque ferro».

Virgilio (Eneida, IV, 441-446) y Catulo (Carmina, LXIV, 105-109) exaltan la resistencia épica de la encina a los embates de los vientos huracanados, en la línea de cultivar la metáfora del árbol que sufre las acometidas de las fuerzas de la naturaleza.

La vigencia y arraigo del símbolo identificador árbol/hombre no se limita, naturalmente, a la antigüedad y a la literatura clásica, sino que, traspasando sus fronteras, llega hasta nuestros días, enraizado en las literaturas más diversas. Por ejemplo, textos del romancero tradicional, de Luis Carrillo de Sotomayor, Alberto Lista, Juan Ramón Jiménez, Alejandro Casona, Gutierre de Cetina, Shakespeare, Víctor Hugo, etc. selecciona Ernesto Jareño en su mencionado estudio ${ }^{11}$, que documentar ampliamente el aserto y nos eximen de nueva búsqueda.

A la vista del cúmulo de antecedentes literarios aducibles, parece claro que nc tiene sentido hablar de una «fuente» precisa de este poema machadiano; más bien hay

${ }^{10} \mathrm{Cfr}$. W. S. SCOTT, The Oral Nature of the Homeric Simile, Leiden, 1974, pp. $70 \mathrm{~s}$.

${ }^{11} \mathrm{C}$ r. «Nueva aproximación al poema machadiano «A un olmo seco»», cit., pp. 469 y ss. 
que referirse a lecturas, cuyos recuerdos sedimentados actúan como un poso, y, desde luego, hemos de hablar, sin duda, de diversificación de influencias. Situándonos en esta perspectiva y sin perder de vista el amplio conjunto de antecedentes literarios, creemos que ha de destacarse un texto especialmente significativo con el que, hasta hoy, no se ha relacionado nuestro poema.

\section{Tolstoi y Machado}

Antonio Machado fue lector interesado de la novela rusa, particularmente atraído por su expresión de una forma de cristianismo que él identifica con el espíritu del pueblo ruso. Tolstoi sería la expresión más perfecta de ese espíritu. En la prosa machadiana las referencias a la novela rusa son abundantes:

En «Sobre literatura rusa», amplio resumen, de la mano del propio Machado, de la conferencia que había pronunciado en la «Casa de los Picos de Segovia» el 6 de abril de $1922^{12}$, cita a Turguénev, Dostoievski, Tolstoi, Pushkin, Lermontov, Chejov, Gorki ${ }^{13}$. En dicha conferencia, Tolstoi es el autor más citado (cinco veces) y se menciona explícitamente su novela La guerra y la paz dos veces, así como a su personaje el príncipe Andrés: «recordad la hermosa muerte del príncipe Andrés» ${ }^{14}$. Entre las Prosas sueltas de preguerra figura un breve texto, donde, de nuevo, se ocupa de Tolstoi: «Dos preguntas de Tolstoi: ¿Qué es el arte? ¿Qué debemos hacer?» ${ }^{15}$. Una rememoración de la «literatura rusa prerrevolucionaria de inspiración evangélica» encontramos en «Sobre una lírica comunista que pudiera venir de Rusia» ${ }^{16}$, donde se aborda la relación cristianismo-marxismo, idea sobre la que vuelve a insistiren Apuntes inédito ${ }^{17}$. De nuevo informa Machado sobre sus lecturas de novela rusa (El adolescente, de Dostoievski, en esta ocasión) en su Carta a David Vigodski. Leningrado, fechada en $1937^{18}$. En el discurso pronunciado en Valencia en la sesión de clausura del Congreso Internacional de Escritores, bajo el lema «escribir para el pueblo» pronuncia Machado unas palabras que evidencian que, por esas fechas, ha sintetizado ya su antigua idea del espíritu del pueblo ruso y el cristianismo en una concepción social, y en las que aparece, una vez más, el nombre de Tolstoi ${ }^{19}$. Nuevas menciones y citas textuales de Dostoievski, Turguenev y Tolstoi encontramos en «Sobre la Rusia actual» (septiembre de 1937) ${ }^{20}$,

\footnotetext{
${ }^{12}$ MACHADO, Antonio, Poesía y Prosa. Edición crítica de Oreste MACRÍ, Espasa-Calpe, Clásicos castellanos, M. 1989. Vol. III, Prosas Completas (1893-1936), pp. 1231 y ss.

${ }^{13}$ Las curiosas grafías con que A. Machado cita a los escritores rusos tal vez pudieran conducirnos a identificar la traducción en que tomó contacto con ellos por vez primera. Pero éste no es nuestro tema.

${ }^{14}$ Op. cit., p. 1236.

${ }^{15}$ Cfr. MACHADO, Antonio, Poesía y Prosa, op. cit., III, pp. 1612 y ss. y p. 1883.

${ }^{16} \mathrm{ID}$. ID., op. cit., III, pp. 1805 y ss.

${ }^{17}$ ID. ID., Op. cit., IV, p. 2145.

${ }^{18}$ ID. ID., Op. cit., IV, p. 2180.

${ }^{19}$ ID. ID., Op. cit., IV, p. 2198.

${ }^{20} \mathrm{ID}$. ID., Op. cit., IV, p. 2215 y ss.
} 
donde explaya la oposición «Nietzsche contra Tolstoi», es decir «Roma y Berlín, las dos fortalezas paganas, la germánica y la latina del cristianismo occidental contra el foco ruso del cristianismo auténtico» ${ }^{21}$, o sea, comunismo-espíritu contra fascismogermanismo. Junto a Gogol, Turguenev y Dostoievski, una vez más aparece citado Tolstoi, entre los admiradores de Pushkin, en Lo que hubiera dicho Juan de Mairena en $1931^{22}$. En fin, de pasada, se cita a Tolstoi en Desde el mirador de la guerra. Lo que recuerdo yo de Pablo Iglesias ${ }^{23}$.

No puede cabernos duda de que Antonio Machado había alcanzado un alto grado de familiaridad con los grandes novelistas rusos, y en particular con Tolstoi, cuya obra cita o parafrasea con frecuencia. Esta actitud del poeta sevillano se enmarca en un contexto español, y europeo occidental, muy favorable a la valoración y difusión de los escritos de los grandes narradores rusos. Josefina Pérez Sacristán en su estudio introductorio a la edición de Anna Karénina ${ }^{24}$, destaca la temprana difusión de sus escritos en Francia y, a través de las versiones francesas, en España, donde Tolstoi fue el preferido. A La revolución y la novela en Rusia dedica E. Pardo Bazán un ciclo de conferencias en el Ateneo de Madrid, en 1886, según la citada J. P. Sacristán, quien nos ilustra sobre la influencia de Tolstoi en Galdós ( $L a$ incógnita, Realidad), subraya la admiración que sintieran por Tolstoi Unamuno, Baroja o Clarín y nos informa del importante papel divulgador de los escritos de los novelistas rusos que llevan a cabo en España revistas tales como La España Moderna, La Lectura, Hermes y Revista de Occidente.

Podemos hacernos una idea aproximada de la amplia difusión que experimentó en España la obra de Tolstoi mediante una simple consulta al Manual de Paláu y Dulcet ${ }^{25}$; sólo de La guerra y la paz se describen treinta ediciones, de las que cuatro vieron la luz entre 1889 y 1905 . Especialmente provechosa resulta la consulta de la obra de Luis Fernández Cifuentes, Teoría y mercado de la novela en España: Del 98 a la República, para conocer la difusión de la literatura rusa en España durante el primer tercio de la presente centuria ${ }^{26}$. Una cuestión diferente es la de la calidad de esas ediciones. Sería interesante conocer, aunque aquí secundario para nosotros, en qué versiones conoció $\mathrm{A}$. Machado los escritos de los novelistas rusos. El mismo alude reiteradamente a la baja calidad de las que circulaban: «Sólo si una obra contiene valores esenciales, hondamente humanos, y una sólida estructura interna puede, aun disminuida por la traducción, ser admirada en lengua extranjera. Tal calidad pudiera tener la novela rusa. Traducida y mal traducida ha llegado a nosotros» ${ }^{27}$. Y en otro lugar: «Aquellos libros que leíamos siendo

${ }^{21}$ Pp. 2219 y 2220.

${ }^{22}$ ID. ID., Op. cit., IV, p. 2358.

${ }^{23}$ ID. ID., Op. cit., IV, p. 2479.

${ }^{24}$ Cfr. TOLSTOI, L., Anna Karénina, Ed. Cátedra, Letras Universales, M. 1986. Introducción por Josefina PÉREZ SACRISTÁN, pp. 44 y ss.

${ }^{25}$ Cfr. Vol. XXIII, pp. 258-267.

${ }^{26}$ Madrid, Gredos, 1982. Cf. en especial cap. II, pp. 149 ss., y cap. III, pp. 299 ss.

${ }^{27}$ MACHADO, A., Poesía y Prosa, op. cit., III, p. 1232. 
niños y que llegaban a nosotros trasegados del ruso al alemán, del alemán al francés y del francés al español chapucero de los más baratos traductores de Cataluña dejaban en nuestras almas, a pesar de tantas torpes decantaciones linguiísticas, una huella muy honda (...). Y es que a través de la más inepta traducción de La guerra y la paz (...) llega a nosotros todavía un mensaje de alma eslava (...). Ni siquiera sabemos si las novelas de Tolstoi o Dostoyevski están bien o mal escritas en su lengua. Suponemos que lo estarán soberbiamente» ${ }^{28}$.

Como puede apreciarse, Machado tenía una idea exacta del problema; más arriba hemos aventurado la hipótesis sobre que, tal vez, las distorsionadas grafías con que aparecen transcritos los nombres de los escritores rusos en las primeras menciones machadianas (corregidas más tarde) pudieran ayudarnos a identificar las primeras traducciones que el poeta manejó. De lo que no puede cabernos duda es de la admiración que A. Machado sentía por los novelistas rusos y de que estaba familiarizado con la lectura de su obra y, de manera especial, con Tolstoi y su novela La guerra y la paz.

\section{«La guerra y la paz» $\mathbf{y}$ «A un olmo seco»}

Retornemos al simbolismo árbol/hombre y convengamos que, en el poema machadiano, no se limita a la identificación, con carácter general, de hombre y árbol, sino que pone en relación el árbol reverdeciente con el hombre caído; a la luz de esta precisión metodológica cobra especial relieve un texto muy preciso de Tolstoi.

En La guerra y la paz, ${ }^{\mathrm{a}}$ parte, capítulos I-III, el príncipe Andrei, viudo y en una situación espiritualmente deprimida, a sus 38 años, efectúa un viaje a Riazán. En el camino de ida contempla un viejo roble, que se resiste, entre el verdor del contorno, a la primavera y que le sugiere muy amargas reflexiones sobre su propia vida. La estancia en Riazán, en cambio, le supone un encuentro con la joven Natasha, que provoca en él una sacudida y un despertar de nuevo a las ilusiones, un «tumulto de confusos pensamientos juveniles y de esperanzas » ${ }^{29}$. Días después, a su regreso de Riazán, tiene lugar el reencuentro en el camino de vuelta con el viejo roble, que sorprendentemente ha reverdecido, y con el que de nuevo se identifica el Príncipe; esta vez sintiendo renacer en él una primavera que creía ya agotada y muerta. Merece la pena citar los pasajes por extenso:

««En el borde del camino se erguía un roble, quizá diez veces más viejo que todos los abedules del bosque, diez veces más grueso y el doble de alto que los demás árboles. Era un árbol gigantesco de dos brazas de circunferencia; sus ramas estaban rotas desde hacía mucho tiempo; el tronco, con la corteza caída en diversos puntos, se hallaba cubierto de viejas y abultadas excrecencias. Con sus enormes y torpes brazos y dedos asimétricos y divergentes retorcidos, parecía, entre los sonrientes abedules, un viejo

${ }^{28}$ ID. ID., Op. cit., IV, pp. 2218 y 2219.

${ }^{29}$ TOLSTOI, L., La guerray la paz, trad. de F. J. Alcántara y P. Laín Entralgo, vol I, Barcelona, Bruguera, $1981,3^{3}$ parte, p. 520. 
monstruo ceñudo y desdeñoso. Sólo él se negaba a someterse a las gracias de la estación y no quería ver ni el sol ni la primavera.

«La primavera, el amor, la felicidad... -parecía decirle el roble-. ¿Cómo no os fatiga este engaño estúpido e insensato de siempre? ¡Todo es lo mismo, todo es engaño! No hay primavera, ni sol, ni alegría. Mirad esos abetos ahogados y muertos, siempre solitarios; miradme a mí, con mis brazos destrozados, tal como crecieron; aquí estoy, sin creer ni en vuestras esperanzas ni en vuestros engaños».

El príncipe Andrei miró varias veces este roble, como si de él esperara algo. Las flores y las hierbas crecían a sus pies, pero el roble sombrío e inmóvil, deforme y obstinado, se mantenía erguido entre ellas.

«Sí, el roble tiene razón -pensó el príncipe Andrei-. Que los demás, que los jóvenes cedan a ese engaño; pero nosotros conocemos la vida, ¡nuestra vida ha terminado!». Y en el alma del príncipe Andrei este roble hizo surgir nuevas ideas desesperadas, pero gratamente tristes. Durante el resto del viaje pareció pasar denuevo revista a toda su vida para llegar a la conclusión de antes, consoladora y resignada, de que no debía comenzar nada; debía vivir así hasta el fin, sin hacer daño ni inquietarse, sin desear nada»» ${ }^{30}$.

\section{(...)}

««Al día siguiente, el príncipe Andrei, después de haberse despedido del conde solamente, partió sin aguardar la salida de las damas.

Eran ya los primeros días de junio cuando, de vuelta a su casa, atravesó los mismos lugares, el mismo bosque de abedules en que aquel viejo y retorcido roble tanto le llamara la atención. Los cascabeles de los caballos sonaron ahora más sordamente que a la ida, mes y medio antes. Todo estaba frondoso y lleno de sombra; hasta los jóvenes abetos, dispersos aquí y allá, armonizaban con la belleza del conjunto, cubiertos con el verde tierno de sus esponjosos brotes.

Era un día de calor y la tormenta debía de ir fraguándose a lo lejos; pero sólo una pequeña nube dejó caer algunas gotas en el polvo del camino y en las jugosas hojas. La parte izquierda del bosque estaba en sombras; pero la otra, mojada por la lluvia, brillaba con cegadores destellos al sol. Un viento muy débil movía apenas las hojas. Toda la naturaleza estaba en flor; lejos y cerca cantaban los ruiseñores.

«Sí, aquí, en este bosque estaba el roble con el que me sentía de acuerdo -pensó el príncipe Andrei- ¿Pero dónde está?, se preguntó mirando a la izquierda del camino.

Y sin él mismo saberlo, sin reconocerlo, admiró el mismo árbol que buscaba. El viejo roble transformado por completo, con sus ramas cubiertas de verde oscuro, se bañaba en la luz del sol vespertino, casi inmóvil y feliz. Ya no se veían sus brazos contorsionados, ni sus excrecencias, ni la desconfianza y el dolor de antes. Nuevas hojas de un verde tierno habían nacido pujantes de su dura corteza centenaria. Parecía imposible que de aquella ruina germinase esta nueva vida. «Sí, es el mismo roble», pensó el príncipe Andrei, y, sin causa alguna, se sintió inundado de un súbito sentimiento primaveral de alegría y renovación.

${ }^{30}$ TOLSTOI, L., La guerra y la paz, trad. cit., $3^{\mathbf{a}}$ parte, cap. 1, pp. 517-518. 
Rememoró en unos instantes todos los minutos decisivos de su vida: Austerlitz y su alto cielo, el rostro lleno de reproches de su mujer muerta, Pierre en la barca y la muchacha entusiasmada por la belleza de la noche: todo lo recordó en un solo instante.

«No, mi vida no ha concluido a los treinta y un años -decidió definitivamente el príncipe Andrei-. No basta con que yo sepa lo que ocurre en mí; deben saberlo todos: Pierre y esta muchacha que quería volar al cielo. Es necesario que todos me conozcan; que mi vida no sea para mí solo, que no vivan ellos tan al margen de mi vida, que mi vida se refleje en todos y que ellos y yo vivamos juntos» $)^{31}$.

Las coincidencias con el texto de Machado son notables: un viejo y destacado árbol, ya decrépito y ahora aparentemente muerto, se identifica con la desesperanza espiritual; paralelo entre su reverdecer primaveral y el renacer de las esperanzas del hombre que lo contempla; vinculación entre este rebrotar y el amor naciente por una mujer, de edad juvenil, en el hombre ya maduro (o al menos de larga y fatigada vida espiritual) frente a la relación Machado, hombre maduro, y la juvenil Leonor. Las impresiones contrapuestas de Andrei son comparables a las de Machado en el trance de la enfermedad de Leonor (años 1911-12) ${ }^{32}$. El roble de Tolstoi es de «corteza centenaria» y el de Machado es un «olmo centenario».

Pero A. Machado ha introducido, como era de esperar, novedades en el tema de Tolstoi:

a) De un lado, su desarrollo descriptivo del olmo viejo, que no coincide, naturalmente, con la del roble de Tolstoi; no obstante, hay un motivo secundario relativamente paralelo: Tolstoi compara el roble viejo («diez veces más viejo que todos los abedules del bosque...») con los «sonrientes abedules»; Machado contrapone la sequedad del olmo con los «álamos cantores».

b) Situación divergente dentro de un marco semejante: Machado sin duda piensa en el renacer de Leonor, no en el propio ${ }^{33}$, como es el caso de Tolstoi, donde se trata de una posibilidad de primavera personal de Andrei mismo.

Para concluir, conviene insistir en que no es nuestro propósito determinar una «fuente» única y precisa. Reiteradamente hemos señalado que estamos ante un tópico de larga y fecunda tradición literaria, que ha llegado hasta A. Machado, y que va a continuar vigente después, como se advierte, por ejemplo -valga un dorado botón de muestra- en'el excelente soneto de Juan Ramón Jiménez «Hierro», número 47 de Sonetos espirituales, que viene introducido precisamente por la cita de Horacio, Od., IV, 4, reproducida más arriba, y en el que se advierten bastantes motivos del poema machadiano.

Vi el roble castigado, que al constante tornar de la sencilla primavera, doraba la oquedad de su madera con su tranquilo corazón fragante.

${ }^{31}$ TOLSTOI, L., La guerra y la paz, trad. cit., $3^{2}$ parte, cap. 3, pp. 520-521.

${ }^{32}$ Cfr. ed. de J. L. CANO, Barcelona, Destino, 1982, p. 108.

${ }^{33}$ Así interpreta O. MACRÍ. Cfr. MACHADO, A., Poesía y Prosa, op. cit., I, p. 170. 
De hierro era el retoñar pujante entre la paz de la estación primera; parecía que el árbol devolviera al cielo el hacha en ramo fulgurante.

Recordé el hacha que con tajo frío abrió mi corazón, roble robusto, primavera de oro y de consuelo.

¡Que mis brazos, verdor del pecho mío, se levantaron solos, en augusto poder, vibrando luz, al vasto cielo!

Ha de hablarse, pues, de reminiscencias de un poso de lecturas; pero ha de reconocérsenos que el parentesco de «A un olmo seco» con el texto de Tolstoi parece más estrecho que cuantos se han señalado hasta ahora. 